\title{
Prospective study to compare abdominal hysterectomy versus non- descent vaginal hysterectomy at a tertiary care hospital
}

\author{
Paresh N. Sheth $^{1 *}$, Prema Ram Choudhary ${ }^{2}$
}

\begin{abstract}
${ }^{1}$ Department of Obstetrics and Gynaecology, Banas Medical College and Research Institute, Palanpur, Gujarat, India
${ }^{2}$ Department of Physiology, Banas Medical College and Research Institute, Palanpur, Gujarat, India
\end{abstract}

Received: 26 January 2021

Accepted: 09 February 2021

\author{
*Correspondence: \\ Dr. Paresh N. Sheth, \\ E-mail: pnsheth50@gmail.com
}

Copyright: () the author(s), publisher and licensee Medip Academy. This is an open-access article distributed under the terms of the Creative Commons Attribution Non-Commercial License, which permits unrestricted non-commercial use, distribution, and reproduction in any medium, provided the original work is properly cited.

\begin{abstract}
Background: Hysterectomy can be performed by vaginal, abdominal and via laparoscopic route. In the current scenario of importance of non-invasive surgery there has been increase in interest and requirement of vaginal hysterectomy for non-prolapsed uterus i.e. Non-descent vaginal hysterectomy (NDVH) due to scarless surgery. Gynecologist across the world continue to use the abdominal approach for a large majority of hysterectomies that may be performed vaginally despite well documented evidence which says that vaginal hysterectomy do have better outcome. This study aimed to find out to compare outcomes of NDVH and Abdominal hysterectomy (AH).

Methods: The study is conducted at department of Obstetrics and Gynecology, at a tertiary care hospital, Palanpur, Gujarat, India, between the periods of May 2018 to December 2019 of 100 patients. 50 Patients who underwent hysterectomy by abdominal route are taken as study group A and 50 Patients who underwent hysterectomy by vaginal routes are taken as group B.

Results: Out of 100 women we have studied, duration of surgery, intra operative blood loss, intra operative complications, postoperative morbidity and duration of hospital stay, time required to resume normal work are less in group B (NDVH).

Conclusions: It can be concluded that NDVH is feasible, safe and better alternative to abdominal hysterectomy for benign gynecological conditions. It also provides greater efficacy and safety with minimal invasiveness.
\end{abstract}

Keywords: Abdominal hysterectomy, Non-descent vaginal hysterectomy, Benign gynecological conditions

\section{INTRODUCTION}

Hysterectomy is currently one of the most common gynecological surgical procedures. ${ }^{1}$ Approximately one in three women has undergone hysterectomy surgery by age 60 with approximately 6,00,000 hysterectomies performed annually in the United States. ${ }^{2}$ Routes for Hysterectomy include abdominal, vaginal, laproscopic or combined approaches. Due to its advantages vaginal hysterectomies are more and more performed now, only drawback is lack of expertise. ACOG in 1990 has established the guidelines stating that vaginal hysterectomy can be performed in patients with mobile uterus whose size no longer than twelve weeks size. ${ }^{3}$ A cochrane database systemic review concluded that vaginal hysterectomy rather than abdominal should be performed whenever feasible to reduce complication, hospital stay and accelerate the patient's return to normal activities. ${ }^{4}$ The present study evaluate outcome of patients who underwent NDVH or $\mathrm{AH}$ at the department of obstetrics and gynecology at a tertiary care hospital, Palanpur, Gujarat, India. The Purpose of this study was to compare the feasibility and safety of NDVH and AH Procedures for the treatment of benign gynecological conditions and to determine the outcome of both procedures. 


\section{METHODS}

This Prospective study conducted in the Department of obstetrics and gynecology, at a tertiary care hospital, Palanpur, Gujarat, India during the period May 2018 to December 2019. Total 100 patients included, out of which 50 undergone $\mathrm{AH}$ (Group A) and 50 undergone NDVH (Group B). All Patients undergone detailed history, physical, ultrasound and routine blood investigations. All Patients were followed up for atleast 3 months.

\section{Inclusion criteria}

Patient having uterine benign disease such as fibroids, adenomyosis, menorrhagia and DUB. Gynecological symptoms that justified hysterectomiesm. Patient without fertility requirement

\section{Exclusion criteria}

Malignancy of uterus or cervix, uterine size more than 12 weeks gestation size, Nullipara or no prior vaginal delivery, previous caesarian delivery, Patient with fertility requirement. Patients with $\mathrm{AH}$ selected with following clinical criteria- fixed uterus, unmarried women, large size of uterus, vaginal stenosis.

Patients with NDVH selected with following criteriafreely mobile uterus, more than one vaginal delivery.

Parameters such as time taken for surgery "intra operative injury or blood loss, post-operative pain, bleeding and wound infections, duration of hospital stay and other follow up parameters like pain and other psychosexual problems were compared".

\section{RESULTS}

Present study included total 100 patients and divided them in two groups, one group underwent abdominal hysterectomy (50 patients) and other group underwent vaginal hysterectomy (50 patients).

Table 1: Baseline characteristics.

\begin{tabular}{|llll|}
\hline & $\begin{array}{l}\text { Group A } \\
(\mathbf{A H})\end{array}$ & $\begin{array}{l}\text { Group B } \\
\text { (NDVH) }\end{array}$ & $\begin{array}{l}\text { Total } \\
(\%)\end{array}$ \\
& $\mathbf{N}(\mathbf{\%})$ & $\mathbf{n = 5 0}$ & $\mathbf{n = 1 0 0}$ \\
\hline Age (years) & & & \\
\hline $25-40$ & $12(24)$ & $13(26)$ & 25 \\
\hline $41-50$ & $30(60)$ & $35(70)$ & 65 \\
\hline $51-60$ & $8(16)$ & $2(4)$ & 10 \\
\hline Parity & & & \\
\hline 1 & $6(12)$ & $2(4)$ & 8 \\
\hline 2 & $8(16)$ & $10(20)$ & 18 \\
\hline 3 and more & $36(72)$ & $38(76)$ & 74 \\
\hline
\end{tabular}

Table 1 shows that in Group B (NDVH) $70 \%$ of patients having age group between 41 to 50 years and $26 \%$ in age group 25 to 40 years and $4 \%$ in the age group 51 to 60 years. In Group A (AH) $60 \%$ is in the age group 41 to 50 years, $24 \%$ in the age group 25 to 40 years and $16 \%$ in the age group of 51 to 60 years. In parity $72 \%$ in Group A (AH) have 3 or more deliveries and $76 \%$ in Group B (NDVH) have 3 or more deliveries.

Table 2: Time taken for surgery.

\begin{tabular}{|llll|}
\hline \multirow{2}{*}{ Time (hours) } & AH & NDVH & $\%$ \\
\cline { 2 - 4 } & N (\%) & N (\%) & \\
\hline $\mathbf{1}$ & $15(30)$ & $40(80)$ & 55 \\
\hline $\mathbf{1}$ to 2 & $33(66)$ & $10(20)$ & 43 \\
\hline $\mathbf{2}$ to 3 & $2(4)$ & $0(0)$ & 2 \\
\hline
\end{tabular}

Table 3: Complaints and indications.

\begin{tabular}{|lll|}
\hline & $\begin{array}{l}\text { Group A } \\
(\mathbf{A H})\end{array}$ & $\begin{array}{l}\text { Group B } \\
(\mathbf{N D V H})\end{array}$ \\
\hline $\mathbf{N}(\boldsymbol{\%})$ & $\mathbf{N}(\%)$ \\
\hline Menorrhagia & $32(64)$ & $40(80)$ \\
\hline $\begin{array}{l}\text { DUB (Polymenorrhoea } \\
\text { and Dysmenorrhoea) }\end{array}$ & $8(16)$ & $5(10)$ \\
\hline Fibroid & $5(10)$ & $3(6)$ \\
\hline Adenomyosis & $2(4)$ & $2(4)$ \\
\hline Cervical Polyp & $3(6)$ & $0(0)$ \\
\hline
\end{tabular}

Table 4: Intra-operative factors.

\begin{tabular}{|c|c|c|}
\hline & $\begin{array}{l}\text { Group A } \\
\text { (AH) }\end{array}$ & $\begin{array}{l}\text { Group B } \\
\text { (NDVH) }\end{array}$ \\
\hline & $\mathbf{N}(\%)$ & $\mathbf{N}(\%)$ \\
\hline $\begin{array}{l}\text { Blood loss (more than } \\
100 \mathrm{ml} \text { ) }\end{array}$ & $10(20)$ & $5(10)$ \\
\hline Pain perception & $10(20)$ & $6(12)$ \\
\hline Any organ injury & 0 & 0 \\
\hline
\end{tabular}

Table 5: Post-operative criteria.

\begin{tabular}{|c|c|c|}
\hline \multirow[t]{2}{*}{ Stay (in days) } & $\begin{array}{l}\text { Group A } \\
\text { (AH) }\end{array}$ & $\begin{array}{l}\text { Group B } \\
\text { (NDVH) }\end{array}$ \\
\hline & $\mathbf{N}(\%)$ & $\mathbf{N}(\%)$ \\
\hline 2 & $25(50)$ & $40(80)$ \\
\hline 2 to 4 & $20(40)$ & $8(16)$ \\
\hline$>4$ & $5(10)$ & $2(4)$ \\
\hline $\begin{array}{l}\text { Post-operative pain } \\
\text { (after } 2 \text { days) }\end{array}$ & $40(80)$ & $25(50)$ \\
\hline Wound Infection & $10(20)$ & $2(4)$ \\
\hline Fever & $12(24)$ & $5(10)$ \\
\hline
\end{tabular}

Table 2 results suggested that operation time was less in Group B (NDVH) compare to Group A (AH). 80\% case in NDVH group took less than one hour for completion of surgery whereas only $30 \%$ in Group A (AH) took less than one hour for surgery. 
Table 3 suggests that menorrhagia seems to be major complaint and indication for hysterectomy. 64\% in Group $\mathrm{A}$ and $80 \%$ in Group B is having menorrhagia as an indication for hysterectomy.

Table 4 shows that blood loss and pain perception is more during operation in Group A (AH).

Table 5 shows that in Group B (NDVH) $80 \%$ patients discharged within two days but in Group A (AH) only 50\% discharged in two days. $10 \%$ cases in Group A (AH) required more than 4 days admission. Post-operative pain remained after two days of surgery is more in Group A (80\%). Wound infection is also more in Group A (20\%). Mild to moderate pain is present post operatively in $24 \%$ of cases in Group A but only 4\% cases in Group B.

\section{DISCUSSION}

Our study is conducted to understand the efficacy in terms of peri operative and post-operative factors associated with two surgical techniques. i.e. NDVH and AH. This study also aimed to compare the complications associated with both procedures. Table 1 shows that in this study in both groups the age range was between 41 to 50 years. In relation to age similar studies comparing $\mathrm{AH}$ and $\mathrm{NDVH}$ have following results. Hoffman et al NDVH - 41.9 years, AH 42.7 years. ${ }^{5}$ Rupali et al NDVH - 44 years, AH - 42.5 years. ${ }^{6}$ It shows that it is between age 40 to 50 years that most women suffer from abnormal uterine bleeding. Table 1 also shows that $72 \%$ in Group A and $76 \%$ in Group B were multi para. Other studies also show same results. 5.6. In this study Table 2 shows that $30 \%$ in Group $\mathrm{A}(\mathrm{AH})$ and $80 \%$ in Group B (NDVH) shows requirement of equal or less than one hour for surgery and $66 \%$ of Group A and $20 \%$ of Group B required 1 to 2 hours for surgery which is a statistically significant difference. In Table 3 it shows that menorhhagia and DUB (Polymenorrhea and dismenorrhea) were the two main indications for hysterectomy. Similar results were shown by Mehta et al, Shanithini et al. ${ }^{7,8}$ In other studies by Garg and co-workers shows that fibroid and DUB were the main indication for surgery. ${ }^{9}$ In intraoperative complications as shown in Table 4 blood loss was less in Group B (NDVH) only $10 \%$ cases as compared to $20 \%$ cases in Group A (AH) which have more than $100 \mathrm{ml}$ of blood loss during surgery. Chen et al and Riberiro et al and Aloknanda et al also found lesser blood loss in NDVH. ${ }^{10,11}$ As shown in Table 5 hospital stay is less in Group B (80\%) as compared to $50 \%$ in Group A. Mostly due to post operative pain after two days prolongs the stay in Group A (AH). Miskry et al, Benassi and Dawood et al, shows same results. ${ }^{12-14}$ In Table 5 study also shows that only $4 \%$ cases in Group B (NDVH) shows wound infection characterized by vaginal discharge which was well treated by local treatment. 10 cases in Group A have wound infection represented by stitch abscess. In that two cases were having wound gap who had obesity. Statistically significant difference in the incidence of wound infection has found by Garg et al, Taylor et al. ${ }^{9,15}$ There were $24 \%$ cases of fever in Group A and $10 \%$ cases in Group B suggest that post-operative complications were more in Group A (AH).

\section{CONCLUSION}

Our study shows that NDVH has significant difference over AH in duration of time of surgery and decreased post operative morbidity with greater recovery, early mobilization and shorter hospitalization. It can be concluded that NDVH is feasible, safe and more comfortable to indicated patients in expert hands specifically in benign gynecological diseases.

Funding: No funding sources

Conflict of interest: None declared

Ethical approval: The study was approved by the Institutional Ethics Committee

\section{REFERENCES}

1. Wu JM, Wechter ME, Geller EJ, Nguyen TV, Visco AG. Hysterectomy rates in the United States, 2003, Obstet Gynecol. 2007;110;1091-095.

2. Whiteman MK, Hillis SD, Jamieson DJ, Morrow B, Podgornik MN, Brett KM, et al. Inpatient hysterectomy surveillance in the United States, 20002004. Am J Obstet Gynecol. 2008;198:34,e1-34.e7.

3. American College of Obstetricians and Gynecologists. Task Force on Quality Assurance. Quality assurance in obstetrics and gynecology. Amer College of Obstetricians; 1989. American college of obstetricians and gynaecologist, precis. IV, and update in obstetrics DC, The college. 1990.

4. Johnson N, Barlow D, Lethaby A. Surgical approach to hysterectomy for benign gynecological disease. Cochrane Database Syst Rev. 2009(3):CD003677.

5. Hoffman MS, Jaeger N. A new method for gaining entry into the scarred anteriorcul-de-sac during transvaginal hysterectomy. Am J Obset Gynecol. 1990;162(5):1269-70.

6. Rupali D, Shivani A, Bharti MM, Soumendra KS. Non-descent vaginal hysterectomy An experience. J Obstet Gynaencol. 2004;54:376-8.

7. Mehta K, Prakash O, Fatehpuriya DS, Verma L. Comparative study of abdominal hysterectomy and vaginal hysterectomy in non-descent cases a prospective study. Int $\mathrm{J}$ Reprod Contracept Obstet Gynecol. 2017;6:1265-70.

8. Shanthini NF, Poomalar GK, Jayasree M, Bupathy A. Evaluation of complications of abdominal and vaginal hysterectomy. Int $\mathbf{J}$ Reprod Contraception Obstet Gynaecol. 2012;1(1):7-11.

9. Garg PK, Deka D, Malhotra N. Non-descent vaginal hysterectomy for benign condition. A better proposition than abdominal hysterectomy. Obs and Gynae Today. 2002;6:345-6.

10. Chen B, Ren DP, Li JX, Li CD. Comparison of vaginal and abdominal hysterectomy: A prospective nonrandomized trial. Pak J Med Sci. 2014;30:875-9. 
11. Ribeiro SC, Ribeiro RM, Santos NC, Pinotti JA. A randomized study of total abdominal, vaginal and laparoscopic hysterectomy. Int $\mathbf{J}$ Gynecol Obstet. 2003;83(1):37-43.

12. Miskry T, Magos A. Randomized, prospective, double- blind comparison of abdominal and vaginal hysterectomy in women without uterovaginal prolapse. Acta obstetricia et gynecologica Scandinavica. 2003;82(4):351-8.

13. Benassi L, Rossi T, Kaihura CT, Ricci L, Bedocchi L, Galanti B, et al. Abdominal or vaginal hysterectomy for enlarged uteri: a randomized clinical trial. Am J Obstet Gynecol. 2002;187(6):1561-5.

14. Dawood NS, Mahmood R, Haseeb N. Comparison of vaginal and abdominal hysterectomy: peri- and postoperative outcome. J Ayub Med Coll Abbottabad. 2009;21(4):116-20.

15. Taylor SM, Romero AA, Kammerer-Doak DN, Qualls C, Rogers RG. Abdominal hysterectomy for the enlarged myomatous uterus compared with vaginal hysterectomy with morcellation. Am J Obstet Gynecol. 2003;189(6):1579-82.

Cite this article as: Sheth PN, Choudhary PR.

Prospective study to compare abdominal

hysterectomy versus non- descent vaginal

hysterectomy at a tertiary care hospital. Int J Reprod

Contracept Obstet Gynecol 2021;10:885-8. 